\title{
Potencial fitorremediador das plantas predominantes na área do lixão de Inconfidentes/MG
}

Kátia de Lourdes Pereira ${ }^{1}$

Lilian Vilela Andrade Pinto ${ }^{2}$

Ademir José Pereira ${ }^{3}$

\section{1 | Introdução}

O desenvolvimento econômico intensificou a industrialização, a agricultura, a urbanização e os impactos negativos no meio ambiente (SILVA; PEDROSO, 2001). Dentre esses últimos, destaca-se o aumento da polvição do solo devido ao descarte incorreto dos resíduos, nos quais, comumente, são encontrados metais pesados. Os metais pesados constituem elementos que possuem número atômico maior que 202 e peso específico maior que $5 \mathrm{~g} \cdot \mathrm{cm}^{-3}$ (BARCELÓ; POSCHENRIEDER, 1992).

O cromo é um metal resultante da inteperização dos constituintes do solo, o qual a sua presença na natureza de forma livre só pode ser obtida na forma de oxidante, resultante da ação antrópica obtida principalmente em locais que ocorrem as deposições de resíduos de origem industrial (CASTILHO, 2001). O aumento da concentração de cromo no solo pode ocasionar alterações crônicas ou agudas, provenientes da translocação do cromo para organismos (SILVA; PEDROSO, 2001) em solos contaminados.

No município de Inconfidentes ocorreu em 2004 O descarte incorreto de 150 tonéis de substância mal cheirosa no lixão do município, o qual posteriormente foi identificado como pertencente a uma empresa do estado de São Paulo (GAZETA DE OURO FINO, 2004).

Para nortear a minimização dos impactos, tem-se a lei $6.938 / 81$, que estabelece que ao realizar uma intervenção negativa ao meio ambiente fica sobre a responsabilidade do poluidor realizar a recuperação. O artigo 225 da Constituição Federal de 1988 impõe que toda atividade que provoque danos ao ambiente deve ser responsabilizada, tendo que arcar com medidas de mitigação e recuperação dos impactos. Desta forma, em solos contaminados deve ser realizada a remediação visando atender essas legislações.

Assim, vem-se investindo em pesquisas para buscar alternativas mais eficazes que possibilitem remediar os solos. Dentre as novas alternativas, destaca-se a biotecnologia por apresentar menor impacto no ambiente e por utilizar de organismos vivos como bactérias e plantas (GAYLARDE et.al., 2005).

Um exemplo de biotecnologia é a fitorremediação, técnica que emprega as espécies vegetais e obtém a energia necessária para realizar a remediação proveniente do seu próprio metabolismo quando realiza a fotossíntese. Essa tecnologia consiste na absorção ou trans-

Instituto Federal de Ciências e tecnologia campus Inconfidentes MG - Inconfidentes MG | katiaitumirim@gmail.com Instituto Federal de Ciências e tecnologia campus Inconfidentes MG - Inconfidentes MG | lilianvap@gmail.com Instituto Federal de Ciências e tecnologia campus Inconfidentes MG - Inconfidentes MG | ademir.pereira@ifs.ifsuldeminas. edu.br 
formação dos metais pesados pelo sistema radicular e rizosfera das plantas proporcionando limpeza ou remediação do local (ACCIOLY; SIQUEIRA, 2000). A fitorremediação apresenta vantagens e limitações (Tabela 1), sendo que as espécies devem apresentar características desejáveis (Tabela 2), as quais naturalmente são difíceis de serem reunidas em uma única espécie. Desta maneira deve-se dar preferência aquelas que reúnem o maior número dessas características conforme Miller (1996) apud Pires (2003).

\begin{tabular}{l|l}
\hline \multicolumn{1}{c|}{ VANTAGENS } & \multicolumn{1}{c}{ LIMITAÇÕES } \\
\hline $\begin{array}{l}\text { Usado em grandes áreas, custo é 20 a 50\% inferior } \\
\text { quando comparado com os demais métodos de } \\
\text { recuperação (PEREIRA, 2005) }\end{array}$ & $\begin{array}{l}\text { Os metais devem estar acessíveis às planta } \\
\text { (ANSELMO et al., 2005) }\end{array}$ \\
\hline $\begin{array}{l}\text { As plantas ajudam na conservação do solo } \\
\text { (DINARDI et al., 2003) }\end{array}$ & $\begin{array}{l}\text { A concentração das toxinas devem estar dentro } \\
\text { limites de tolerância da planta usada (DINARDI et } \\
\text { al., 2003) }\end{array}$ \\
\hline $\begin{array}{l}\text { Produz a sua própria energia através da } \\
\text { fotossíntese (PEREIRA, 2005). }\end{array}$ & $\begin{array}{l}\text { Depende da atividade do elemento na solução do } \\
\text { solo (PEREIRA, 2005). }\end{array}$ \\
\hline $\begin{array}{l}\text { Boa aceitação publica (DINARDI et al 2003); Maior } \\
\text { eficiência ao longo do tempo (ZEITOUNI, 2003) }\end{array}$ & $\begin{array}{l}\text { O tempo para despolvição satisfatória pode ser } \\
\text { longo (ANSELMO et al., 2005), sendo ineficiente } \\
\text { para contaminantes fortemente adsorvidos } \\
\text { (ZEITOUNI, 2003) }\end{array}$ \\
\hline $\begin{array}{l}\text { Plantas geneticamente modificadas promovem } \\
\text { maior eficácia (SCHROEDER, 2003). }\end{array}$ & $\begin{array}{l}\text { As plantas são seletivas aos metais, em altas } \\
\text { concentrações a vegetação poderá não se } \\
\text { desenvolver (ANSELMO et al., 2005) }\end{array}$ \\
\hline $\begin{array}{l}\text { Pode fitorremediar mais de um polvente no } \\
\text { mesmo local (LAMEGO, 2007) }\end{array}$ & $\begin{array}{l}\text { A metabolização de compostos pode ser mais } \\
\text { problemática do que os compostos originais. } \\
\text { Podendo se propagar na cadeia alimentar } \\
\text { (DINARDI et al., 2003) }\end{array}$ \\
\hline
\end{tabular}

Tabela 1: Vantagens e limitações da fitorremediação | Fonte: Elaboração própria

Deverá ser capaz de secretar fitoquelatinas (SCHROEDER, 2003)

Resistência as pragas e doenças, apresentado boa acumulação mesmo em baixas quantidades (WENGER et al.,1997 Apud ACCIOLY \& SIQUEIRA, 2000)

Facilidade na aquisição de propágulos, adaptabilidade, fácil erradicação ou colheita (CRUVINEL, 2009)

Os metais pesados devem ser transportados para os galhos e folhas, facilitando sua remoção (SCHROEDER, 2003)

Tabela 2: Características desejáveis das espécies fitorremediadoras | Fonte: Elaboração própria

No Brasil, há a necessidade de estudar espécies fitorremediadoras ainda não exploradas comercialmente, conforme descreveram Lamego et al. (2007). Assim, dentre as espécies ainda não avaliadas quanto ao potencial fitorremediador de cromo, tem-se Vernamia Polysphaera, Solanum paniculatiom e Ricinus Communis, espécies predominantes na área degradada pelo descarte incorreto de resíduos sólidos do município de Inconfidentes, MG. 


\section{2 | Material e métodos}

O estudo foi desenvolvido no município de Inconfidentes, localizado na região sul do estado de Minas Gerais, na margem da Rodovia $\mathrm{MG} / 290$, com coordenadas geográficas de $22^{\circ}$ 19' 01" S 46019' 40" W. Segundo a classificação de Koppen, o clima é tropical de altitude (cwb), com as seguintes características: temperaturas médias no verão de $22^{\circ} \mathrm{C}$ e no inverno de $16,5^{\circ} \mathrm{C}$. Os índices pluviométricos variam de 1400 a $1700 \mathrm{~mm}$ (PORTAL INCONFIDENTES, 2009).

$\mathrm{Na}$ área do antigo lixão de Inconfidentes, realizou-se a seleção de três espécies predominantes da área. As espécies selecionadas para a coleta de folhas em 3 pontos distintos (montante, jusante e no centro do lixão) foram: Ricinus Communis (Mamona), Vernamia Polysphaera (Assa-peixe) e Salanum Paniculatiom (Jurubeba).

A espécie Vernamia Polysphaera é nativa, arbustiva, conhecida popularmente por assapeixe e pode atingir até $4 \mathrm{~m}$ de altura. Ocorre na região sudeste, especialmente em pastagens e possui facilidade em recuperar-se quando ocorrido o corte da parte aérea (ALMEIDA, 1989).

A espécie Solanum paniculatiom pertence à família Solanaceae, comumente conhecida por jurubeba, é nativa da região norte e nordeste, no entanto se espalhou por todo o país, sendo frequentemente encontrada em pastagens e áreas desocupadas. É uma espécie arbustiva que pode alcançar até $3 \mathrm{~m}$ de altura (KISSMANN; GROTH, 1999).
Ricinus Communis, conhecida por mamona, pertence à família Euphorbiaceae, é originada do continente africano e já se espalhou por todo território nacional em especial em estradas. É uma arbustiva tropical que pode atingir até $3,5 \mathrm{~m}$ de altura, apresenta raízes pivotantes e profundas e se adaptam a características do ambiente (KISSMANN; GROTH,1999).

As amostras de folhas (três folhas) das espécies foram coletadas, embaladas e encaminhadas para o laboratório de análise foliar da Universidade Federal de Lavras (UFLA) para obter a quantificação do cromo total nas folhas através do método de massa seca cinza seguindo a metodologia adotada por Bonatto et al. (1997).

Para o estudo, adotou-se o delineamento inteiramente casualisado, sendo as variáveis submetidas à análise estatística através do programa Sanest (ZONTA; MACHADO, 1984) e comparadas pelo teste de Tukey a $5 \%$ de significância.

\section{3 | Resultados e discussão}

Os valores das análises foliares das espécies de Ricinus Communis, Vernamia Polysphaera e Solanum Paniculatiom presentes no depósito de lixo do município de Inconfidentes apresentaram diferença significativa para acúmulo de cromo presente na matéria seca foliar (Tabela 3), indicando que as espécies extraem e acumulam esse metal em quantidades diferenciadas.

A Vernamia Polysphaera (Assa-peixe) apresentou diferença significava, com maior acúmulo de metal em seu tecido, quando com-

\begin{tabular}{l|l|l}
\multicolumn{1}{c|}{ ESPÉCIES } & \multicolumn{1}{c|}{ NOME COMUM } & \multicolumn{1}{c}{ ACÚMULO DE CROMO (PPM) } \\
\hline Vernamia Polysphaera & Assa-peixe & $3,075 \mathrm{a}$ \\
\hline Solanum paniculatiom L & Jurubeba & $2,950 \mathrm{ab}$ \\
\hline Ricinus communis & Mamona & $2,700 \mathrm{~b}$ \\
\hline CV & & 0,37095 \\
\hline
\end{tabular}

Tabela 3: Acúmulo de Cr nas folhas de Vernamia Polysphaera, Solanum Paniculatiom L e Ricinus Communis, plantas da área do lixão de Inconfidentes, MG. | Fonte: Elaboração própria | Médias seguidas pela mesma letra na coluna não diferem estatisticamente entre si, pelo teste de Tukey $(\mathrm{P}<0,05)$.

parada com a concentração foliar das demais plantas analisadas. Possivelmente, esse resultado para Vernamia Polysphaera (assa-peixe) tenha sido em função de a espécie apresentar maior potencial para fitorremediação do que as demais espécies estudadas, mesmo o cromo estando em baixas concentrações no solo, $20 \mathrm{mgkg}^{-1}$, dados do Relatório de Investigação 
Ambiental Exploratória/Aterro de Inconfidentes/MG-2005. Segundo Wenger et al. (1997) apud Accioly e Siqueira (2000), as espécies para serem consideradas potencialmente fitorremediadoras devem realizar a translocação dos metais para seu tecido celular mesmo esse estando em pequenas quantidades no solo, o que foi observado nas espécies estudadas.

Os baixos valores do metal cromo nas foIhas das espécies estudadas (Tabela 3 ) podem ter sido influenciados pelo comportamento do elemento cromo, que apresenta tendência em ficar fortemente adsorvido no solo, proporcionando pouca mobilidade para absorção das plantas quando em contato com as raízes, conforme ATSDR (2000) apud Silva e Pedroso (2001). Os órgãos das plantas não apresentam o mesmo comportamento quanto à absorção e acumulação de metais, sendo nas raízes a maior acumulação, local onde ocorre o primeiro contato com as substancias químicas presentes no solo (BARCELÓ; POSCHENRIEDER, 1992; PETERSON; GIRLING, 1981 apud KELLER et al., 1997), havendo pequena translocação de cromo das raízes para a parte aérea (PETERSON; GIRLING, 1981, apud KELLER et al., 1997). Com essas considerações, estudos futuros poderiam analisar o potencial fitorremediador das espécies avaliadas neste estudo, avaliando a quantidade de metal nas raízes.

\section{4 | Conclusão}

As espécies Ricinus Communis, Vernamia Polysphaera e Solanum Paniculatiom por predominarem na área do lixão apresentaram maior adaptabilidade ao ambiente com características adversas.

A espécie Vernamia Polysphaera acumulou maior quantidade de cromo na parte aérea do que as demais espécies estudadas.

\section{Agradecimentos}

À FAPEMIG pela concessão da bolsa.

\section{Referências bibliográficas}

ACCIOLY,A.M.A; SIQUEIRA J.O. Contaminação química e biorremediação do solo. Tópicos em Ciência do Solo, v.1, p.299-351, 2000.

ALMEIDA, J.S. Plantas daninha. 2 ed. São Paulo: Editora Ceres, 1989.

ANSELMO,A.L.F.; JONES,C.M.

Fitorremediação de solos contaminados, Porto Alegre, RS, 2005.In: XXV ENCONTRO NACIONAL DE ENGENHARIA E PRODUÇÃO PORTO ALEGRE, RS. Rio Grande do Sul 2005 ENGEP P $5253-5280$.

BARCELÓ, J.; POSCHENRIEDER. C.; Suelos y plantas 2 (1992), p. 345.

BONATTO,P. S. et al. Quantificação de metais pesados em plantas potencialmente fitorremediadoras no Depósito de Resíduos sólidos do Aura- Belém/Pará. 1997. Tese (Doutorado). Universidade do Estado do Pará, [s.I.].

CASTILHOS, D.; et al. Acúmulo de cromo e seus efeitos na fixação biológica de nitrogênio e absorção de nutrientes em soja. Revista Brasileira de Agrociência, v.7 n. 2, p. 121-124, mai./ago., 2001.

\section{CRUVINEL, D. F. C. Avaliação da}

fitorremediação em solos submetidos à contaminação com metais. Dissertação (Mestrado). 2009. Universidade de Ribeirão Preto, Ribeirão Preto.

DINARDI, A.L. et al. Fitorremediação. Centro Superior de Educação Tecnológica (CESET) UNICAMP, Campinas, 2003.In: $3^{\circ}$ FÓRUM DE ESTUDOS CONTÁBEIS. Faculdade integrada Claretiana, Rio Claro, São Paulo.

GAYLARDE, C.C.; BELLINASO, M. DE L.; MANFIO, G.P. Aspectos Biológicos e técnicos de biorremediação de xenobíoticos. Biotecnologia Ciências \& Desenvolvimento p.34, jan./jun. 2005. 
KELLER, W. et al. O cromo nos resíduos sólidos de curtumes - imobilização em materiais cerâmicos. In: $19^{\circ}$ CONGRESSO BRASILEIRO DE ENGENHARIA SANITÁRIA E AMBIENTAL ABES - Associação Brasileira de Engenharia Sanitária e Ambiental III - 049 Escola de Engenharia da Universidade Federal de Minas Gerais, Belo Horizonte - MG 1997.

KISSMANN, K. G.; GROTH, D. Plantas infestantes e nocivas. São Paulo: Basf, 1999.

LAMEGO, F.P; VIDAL, R.A. Fitorremediação: plantas como agentes de despolvição?

Pesticidas: Revista de Ecotoxicologia e Meio Ambiente, Curitiba, v. 17, p. 9-18, jan./dez. 2007.

Lei que Institui sobre a Política Nacional do Meio Ambiente, seus fins e mecanismos de formulação e aplicação, e dá outras providências. Brasília:

Disponível <www.planalto.gov.br/ccivil_03/ LEIS/L6938>.

Acesso em: 20 set. 2009

PEREIRA, B. F. Potencial fitorremediador das culturas de feijão-de-porco, girassol e milho cultivadas em latossolo vermelho contaminado com chumbo. Instituto agronômico, 68 p. 2005.

PIRES, F.R. et al. Fitorremediação de solos contaminados com herbicidas.Planta

Daninha, Viçosa, v. 21, n. 2, ago. 2003.

PORTAL INCONFIDENTES 2009.

Caracterização da região Inconfidentes. 2010. Disponível em <www.inconfidentes. mg.gov.br/2009>.

Acesso em: 28 set. 2012.

SCHROEDER, J. Plantas poderão limpar áreas contaminadas com metais pesados. Pesquisadores da Universidade da Califórnia (Estados Unidos), 2003.

SILVA, C.S.; PEDROSO,M.F Ecotoxicologia de cromo e seus composto 2001. Caderno de Referencia Ambiental, v. 6, Salvador, 2001
ZEITOUNI, C. F. Eficiência de espécies vegetais como fitoextratoras de cádmio, chumbo, cobre, níquel e zinco de um Latossolo Vermelho Amarelo distrófico. 2003. 91p. Dissertação (Mestrado). Instituto Agronômico - Agricultura Tropical e Subtropical [s.l].

ZONTA, E. P.; MACHADO, A. A. SANEST: sistema de análise estatísticas para microcomputadores. Pelotas: UFPEL, 1984. 